\title{
Knowledge regarding fertility preservation in cancer patients: a population-based survey among Brazilian people during the Pink October awareness event
}

\author{
Mauricio B Chehin ${ }^{1,2}$, Tatiana CS Bonetti ${ }^{1,2}$, Paulo C Serafini ${ }^{1,3}$, Eduardo LA Motta ${ }^{1,2}$ \\ ${ }^{1}$ Huntington - Medicina Reprodutiva. Sao Paulo, SP, Brasil \\ 2Disciplina de Ginecologia Endocrinológica, Departamento de Ginecologia, Escola Paulista de Medicina da \\ Universidade Federal de São Paulo (UNIFESP-EPM). Sao Paulo, SP, Brasil \\ ${ }^{3}$ Disciplina de Ginecologia, Departamento de Obstetrícia e Ginecologia, Faculdade de Medicina, Universidade de \\ Sao Paulo (FMUSP). Sao Paulo, SP, Brasil
}

This study was presented during the "Annual Oncofertility Consortium Conference" held in Chicago, IL (USA), November 2014

\begin{abstract}
Objective: The aim of this study was to assess the knowledge about the risk of infertility in cancer patients after treatment, and the options for fertility preservation based on a survey carried out during the 2013 Pink October campaign.
\end{abstract}

Methods: This survey was carried out during the 2013 Pink October event in the most important public park of São Paulo, Brazil. Approximately 900 people expressed interest in learning about breast cancer prevention and fertility preservation by participating in workshops, and 242 people filled out a questionnaire.

Results: Most of the respondents (78.5\%) were women, and one-fourth $(25 \%)$ had at least one relative with gynecological cancer. Among women over 40 years of age, $86.3 \%$ had been screened for breast cancer at some point. However, few participants (34.0\%) were aware that cancer treatment can lead to infertility or had heard about fertility preservation options (22.0\%). Having a relative with cancer did not influence their knowledge about fertility preservation $(22.4 \%$ versus $21.3 \% ; p=0.864)$. However, a higher educational level was significantly associated with more knowledge about the effects of cancer on fertility and options for fertility preservation.

Conclusions: The majority of participants did not have knowledge about the impact of oncologic treatment on fertility and did not know that there are options to preserve fertility in cancer patients. Awareness of infertility risk factors is an essential first step to safeguard future fertility, and therefore, more educational initiatives are needed to spread knowledge about oncofertility.

Keywords: oncofertility, cancer, fertility preservation, survey

\section{INTRODUCTION}

Advances in cancer therapy over the past two decades have led to a remarkable improvement in survival rates. Indeed, over the past 5 years, overall rates of death attributable to cancer in women have fallen by $>1.6 \%$ per year (Siegel et al., 2012). In addition to increasing survival, addressing the diverse psychological and physical effects of malignancy is now a priority to optimize the quality-of-life of cancer survivors. The damaging effects of cancer treatments and, occasionally, of the disease process itself on reproductive function are well recognized (Grynberg, 2016). Loss of reproductive potential after cancer treatment represents an important issue for the patients' well-being, and it negatively affects quality-oflife in young survivors (Tschudin \& Bitzer, 2009; Niemasik et al., 2012).

The concept of oncofertility was proposed a decade ago (Woodruff, 2010), and with the developments in assisted reproductive technologies, there are several fertility preservation approaches available for cancer patients wishing to have children in the future. Fertility is thus recognized as a critical component of quality-of-life for cancer survivors, and fertility preservation should be considered a natural extension of cancer care (RodriguezWallberg \& Oktay, 2010).

Although fertility should be at the forefront of cancer attention, and although international guidelines recommend that patients should be informed both of the risk of subsequent treatment-related infertility and the available options for fertility preservation (Loren et al., 2013; Peccatori et al., 2013; Lambertini et al., 2016), oncologists often lack knowledge and fail to provide information to patients about infertility risks prior to the start of cancer treatment (Anderson et al., 2008; Adams et al., 2013; Garrido-Colino et al., 2016; Ghazeeri et al., 2016; Warner et al., 2016). A survey performed by the France National Institute of Cancer demonstrated that a minimal percentage of female cancer patients $(2.2 \%)$ had been informed about fertility preservation before treatment (Peretti-Watel, 2014). In practice, few cancer patients who are at risk of infertility are informed of these risks before treatment onset, and even fewer are referred to a specialist and offered options to preserve their fertility (Anderson et al., 2008; Rodriguez-Wallberg \& Oktay, 2010; Corney \& Swinglehurst, 2014; Preaubert et al., 2016).

Breast cancer is the most common type of cancer in women, and the second most common type of cancer overall, with nearly 1.7 million new cases diagnosed in 2012 (Ferlay et al., 2013). Breast cancer survival rates vary widely throughout the world, ranging from $80 \%$ or higher in North America, Sweden and Japan, to approximately $60 \%$ in middle-income countries, and below $40 \%$ in lowincome nations (Coleman et al., 2008). In less developed countries, a lack of early detection programs, adequate diagnosis and treatment facilities lead to low survival rates. The high prevalence of this disease prompted the development of a world-wide annual campaign in 1997, named Pink October, to increase awareness about Breast Cancer, which instituted October as the Breast Cancer Awareness Month.

Aiming to join this collaborative effort, the Huntington Reproductive Medicine group promoted a Pink October campaign in 2013, to inform patients about breast cancer prevention and fertility preservation in the major public park of São Paulo, Brazil. The event was open to everyone in the park (men and women), and approximately 900 people expressed interest in learning about breast cancer prevention and fertility preservation, participating in workshops and talking to fertility specialists. During this campaign, the participants were invited to answer a questionnaire about fertility preservation in cancer patients. The aim of this study was to assess the overall knowledge about the risks of infertility in cancer patients 
following oncologic treatment and the options for fertility preservation by utilizing a survey during the Huntington Reproductive Medicine Pink October campaign.

\section{MATERIALS AND METHODS}

This was a qualitative study based on a survey about fertility preservation in cancer patients carried out during the 2013 Pink October event held in Ibirapuera park, São Paulo, Brazil. The instrument was an investigator-designed, self-reported questionnaire including a total of 24 questions about sociodemographic characteristics (6 questions), medical history ( 11 questions), life style (5 questions) and awareness concerning the subject of fertility preservation in cancer patients ( 3 questions). The participants who answered the questionnaire authorized the use of data in scientific publications, respecting the anonymized handling of data, according to the rules of ethics.

The questionnaires were available in paper-andpencil format, and no patient identifiers were included to ensure anonymity. A total of 242 participants answered the questionnaire. The survey included questions on demographic characteristics, such as gender, age, educational status, occupation, and the following cancerrelated questions: (1) Do you have a relative with gynecological cancer? and (2) Have you been previously screened for breast cancer? The survey also included questions on fertility preservation in cancer patients: (1) Have you heard about fertility preservation in cancer patients? (2) Do you know that patients can be infertile after cancer treatment? (3) Do you know anyone younger than 40 years who has had cancer?

\section{Statistical analysis}

Descriptive statistics were used to characterize the population. To evaluate how much knowledge patients had about fertility preservation in cancer patients, their answers were presented as percentages. We used a Chisquare test to compare answers between subgroups and $t$-tests to compare continuous variables. The data was analyzed using the SPSS software (version 18, IBM, SPSS, Chicago, IL, USA).

\section{RESULTS}

Two hundred forty-two people answered the survey; $78.5 \%(n=190)$ were women $(42.3 \pm 15.6$ years of age), and $21.5 \%(n=52)$ were men $(45.5 \pm 17.7$ years of age). Most of the participants had a college degree (65.9\%), and one-fourth $(24.6 \%)$ had a relative with gynecological cancer. Among the women who had relatives with a history of gynecological cancer, a higher percentage $(82.7 \%)$ had been screened for breast cancer compared to those who did not have relatives with a history of gynecological cancer $(64.4 \%, p=0.012)$. Among the 95 women over 40 years of age, independent of whether they had relatives with a history of gynecological cancer, $86.3 \%$ had previously been screened for breast cancer. However, only $34.0 \%$ of the participants were aware that cancer treatment can lead to infertility, and only $22.0 \%$ had heard about fertility preservation options (Figure $1 \mathrm{~A}$ and $1 \mathrm{~B}$ ).

Knowledge about the risk of infertility following cancer treatment was similar between women and men $(35.8 \%$ and $26.5 \% ; p=0.214$ ) and between those who had a relative with a history of gynecological cancer and those who did not $(36.2 \%$ and $33.1 \% ; p=0.670)$. Although there was no statistically significant difference, a higher percentage of women had heard about fertility preservation options for cancer patients $(23.5 \%)$ when compared to men $(14.3 \%$; $p=0.147)$, but the percentage was comparable between those who had relatives with a history of gynecological cancer $(22.4 \%)$ and those who did not $(21.3 \% ; p=0.864)$.
Conversely, the level of education attained was positively correlated with both knowledge about the effects of cancer treatment on fertility and familiarity with fertility preservation options for cancer patients (Figure 2A and $2 \mathrm{~B}$ ). It is interesting to note that even among healthcare professionals, the knowledge was the same as that of the general population with a university-level education, in terms of the effects of cancer on fertility $(11 / 24,45.8 \%)$ and fertility preservation for cancer patients $(6 / 24,25.0 \%)$.

\section{DISCUSSION}

Breast cancer is the most common malignancy in women (Rojas \& Stuckey, 2016), and each year Pink October events spread awareness about prevention and treatment of this disease. Considering the impact of emotional impairment, relationship problems, uncertainty about maternity, safety and low self-esteem on the qualityof-life reported by young female cancer survivors (Yee et al., 2012; Deshpande et al., 2015), fertility preservation brings hope and enhances self-competence in cancer treatment decisions. In this context, fertility has been identified as the second most important factor for cancer patients who are considering treatment options, surpassed only by survival (Kim et al., 2016).

In contrast, our study found that only approximately one-third of people have information about fertility impairment after cancer treatment and that approximately $20 \%$ of the respondents were aware that fertility preservation is possible. Unexpectedly, people who had a relative with cancer did not have more knowledge about oncofertility, when compared to those who did not.

Previous studies demonstrated that the amount of information concerning oncofertility given to women by healthcare professionals varies considerably. Oncologists hold little knowledge about fertility preservation techniques, and the referral rates for oncofertility experts remain low (Bastings et al., 2014; Corney \& Swinglehurst, 2014). The main reason for the low rate of oncofertility referrals is the complexity and novelty of some fertility preservation options, which include techniques such as ovarian tissue cryopreservation or oocyte in vitro maturation (Donnez \& Dolmans, 2013), and thus make this discussion about reproductive health in young patients diagnosed with a fertility-threatening disease particularly complex. This discussion should cover topics from basic biology, medical practice planning, health access, and reproductive rights, and include ethical, social, moral, cultural, religious, and personal perspectives (Woodruff, 2015).

Our study also demonstrated that a higher educational level was positively correlated with knowledge about the effects of cancer treatment on fertility and about fertility preservation options for cancer patients. However, in line with the literature, it is interesting to note that healthcare professionals did not have more information about the effects of cancer or cancer treatment on fertility, or about fertility preservation options than the general population with a university-level education. This scenario suggests the need to spread information on oncofertility, as this is a new and complex field in medicine, that addresses the fertility preservation needs of young cancer patients, intersecting the disciplines of oncology and fertility (Woodruff, 2007).

Unfortunately, many patients stated that the discussion of fertility matters was initiated by themselves, their friends, and their families rather than their healthcare providers (Yee et al., 2012), reinforcing the importance of educational initiatives to spread oncofertility concepts to healthcare professionals. In France, a study on an educational initiative to encourage physicians who were involved with treating cancer patients, to refer these patients for fertility consultations, reported an important 
A Knew that cancer treatment can lead to infertility

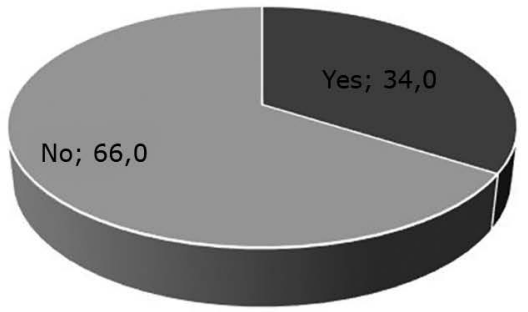

B Heard about fertility preservation

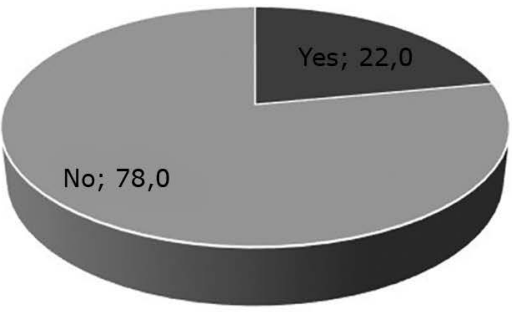

Figure 1. A: Percentage of participants who knew that cancer treatment can lead to infertility. B: Percentage of patients who had heard about fertility preservation options.

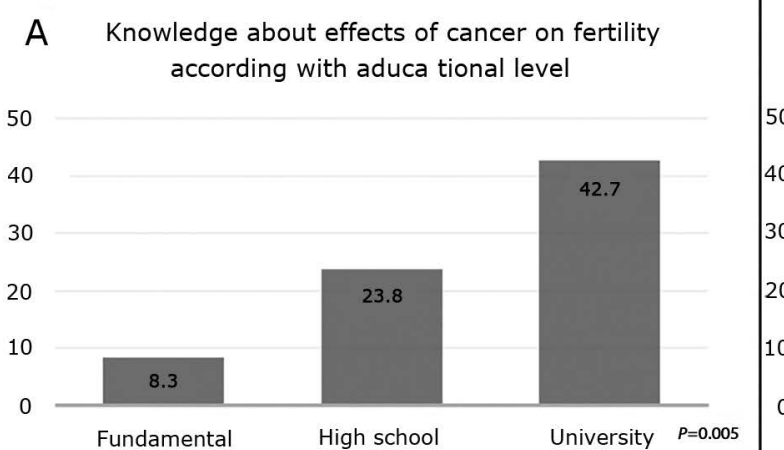

B knowledge about fertility preservation for oncological patients

Figure 2. Graphical representations of the percentage of respondents who had knowledge about the effects of cancer treatment on fertility (A) and fertility preservation options for cancer patients (B).

and positive impact of providing the patient this information before starting treatment. Indeed, the percentage of physicians who always or often informed their patients about the risk of subsequent infertility prior to potentially gonadotoxic treatments increased from $53.8 \%$ to $81.0 \%$, and the percentage of physicians who informed their patients about fertility preservation options increased from $44.9 \%$ to $75.7 \%$ after three years of the program (Preaubert et al., 2016).

Furthermore, several society-based guidelines recommend the discussion of potential fertility impairment at the earliest possible moment after diagnosis, a prompt referral to a qualified specialist if the patient is interested, and the promotion of clinical trials to advance the state of art in fertility preservation (Ethics Committee of American Society for Reproductive, 2013; Loren et al., 2013). Currently, sperm, egg, and embryo banking are standardsof-care for preserving fertility for cancer patients at reproductive age; ovarian tissue cryopreservation is still considered experimental (Kim et al., 2016). Our group has been vitrifying oocytes from cancer patients since it was an experimental procedure (da Motta et al., 2014) and has worked hard to inform healthcare professionals about oncofertility. It is necessary that the medical community acquire knowledge about these issues to inform and refer young cancer patients in an efficient way for fertility preservation.

Making decisions about preserving future fertility requires that patients receive information from many different sources, including their doctors, their families, and society, at a highly emotional time, when they are facing an existential crisis about themselves, their survival, and their future. This survey reveals the lack of oncofertility knowledge among the Brazilian population and supports advocating for a healthcare field that bridges oncology and fertility to discuss reproduction with young cancer survivors. The Brazilian Oncofertility Consortium has advocated for oncofertility concerns in the last several years, not only in the country itself but also working with global partners in the scientific field around the world (Ataman et al., 2016). Valuing the Brazilian oncofertility community, it is important to spread the knowledge about this subject among oncologists, general gynecologists, urologists and others, and this will consequently lead to better fertility support for young, childless cancer patients.

\section{ACKNOWLEDGEMENTS}

We are very thankful to the Huntington Reproductive Medicine Group for promoting the 2013 Pink October event, held in Ibirapuera park, São Paulo, Brazil, and all the professionals who participated of the campaign.

\section{CONFLICT OF INTERESTS}

The authors have no conflict of interests to report.

\section{Corresponding author:}

Mauricio B. Chehin

Huntington Medicina Reprodutiva

São Paulo, SP, Brasil

E-mail: mchehin@huntington.com.br 


\section{REFERENCES}

Adams E, Hill E, Watson E. Fertility preservation in cancer survivors: a national survey of oncologists' current knowledge, practice and attitudes. $\mathrm{Br}$ J Cancer. 2013;108:1602-15. PMID: 23579214 DOI: $10.1038 /$ bjc. 2013.139

Anderson RA, Weddell A, Spoudeas HA, Douglas C, Shalet SM, Levitt G, Wallace WH. Do doctors discuss fertility issues before they treat young patients with cancer? Hum Reprod. 2008;23:2246-51. PMID: 18614615 DOI: 10.1093 /humrep/den252

Ataman LM, Rodrigues JK, Marinho RM, Caetano JP, Chehin MB, Alves da Motta EL, Serafini P, Suzuki N, Furui T, Takae $\mathrm{S}$, Sugishita Y, Morishige KI, Almeida-Santos T, Melo C, Buzaglo $K$, Irwin K, Wallace WH, Anderson RA, Mitchell RT, Telfer EE, Adiga SK, Anazodo A, Stern C, Sullivan E, Jayasinghe $\mathrm{Y}$, Orme $\mathrm{L}$, Cohn R, McLachlan R, Deans R, Agresta $F$, Gerstl B, Ledger WL, Robker RL, de Meneses E Silva JM, Silva LH, Lunardi FO, Lee JR, Suh CS, De Vos M, Van Moer E, Stoop D, Vloeberghs V, Smitz J, Tournaye H, Wildt L, Winkler-Crepaz K, Andersen CY, Smith BM, Smith K, Woodruff TK. Creating a Global Community of Practice for Oncofertility. J Glob Oncol. 2016;2:83-96. PMID: 27284576 DOI: $10.1200 / J G 0.2015 .000307$

Bastings L, Baysal O, Beerendonk CC, Braat DD, Nelen WL. Referral for fertility preservation counselling in female cancer patients. Hum Reprod. 2014;29:2228-37. PMID: 25069500 DOI: $10.1093 /$ humrep/deu186

Coleman MP, Quaresma M, Berrino F, Lutz JM, De Angelis R, Capocaccia R, Baili P, Rachet B, Gatta G, Hakulinen T, Micheli A, Sant M, Weir HK, Elwood JM, Tsukuma H, Koifman S, E Silva GA, Francisci S, Santaquilani M, Verdecchia A, Storm HH, Young JL; CONCORD Working Group. Cancer survival in five continents: a worldwide population-based study (CONCORD). Lancet Oncol. 2008;9:730-56. PMID: 18639491 DOI: $10.1016 / S 1470-2045(08) 70179-7$

Corney RH, Swinglehurst AJ. Young childless women with breast cancer in the UK: a qualitative study of their fertilityrelated experiences, options, and the information given by health professionals. Psychooncology. 2014;23:20-6. PMID: 24038590 DOI: 10.1002/pon.3365

da Motta EL, Bonavita M, Alegretti JR, Chehin M and Serafini P. Live birth after 6 years of oocyte vitrification in a survivor with breast cancer. J Assist Reprod Genet. 2014. 31(10): 13971400 DOI: http://dx.doi.org/10.1007/s10815-014-0314-0

Deshpande NA, Braun IM, Meyer FL. Impact of fertility preservation counseling and treatment on psychological outcomes among women with cancer: A systematic review. Cancer. 2015;121:3938-47. PMID: 26264701 DOI: 10.1002/cncr.29637

Donnez J, Dolmans MM. Fertility preservation in women. Nat Rev Endocrinol. 2013;9:735-49. PMID: 24166000 DOI: $10.1038 /$ nrendo.2013.205

Ethics Committee of American Society for Reproductive Medicine. Fertility preservation and reproduction in patients facing gonadotoxic therapies: a committee opinion. Fertil Steril. 2013;100:1224-31. PMID: 24094423 DOI: $10.1016 /$ j.fertnstert.2013.08.041
Garrido-Colino C, Lassaletta A, Vazquez MÁ, Echevarria A, Gutierrez I, Andión M, Berlanga P; en representación del Comité de Adolescentes de la SEHOP. Current situation on fertility preservation in cancer patients in Spain: Level of knowledge, information, and professional involvement. An Pediatr (Barc). 2016; pii:S1695-4033:30188-6. PMID: 27255351 DOI: $10.1016 /$ j.anpedi.2016.04.019

Ghazeeri G, Zebian D, Nassar AH, Harajly S, Abdallah A, Hakimian S, Skaiff B, Abbas HA, Awwad J. Knowledge, attitudes and awareness regarding fertility preservation among oncologists and clinical practitioners in Lebanon. Hum Fertil (Camb). 2016;19:127-33. PMID: 27376977 DOI: $10.1080 / 14647273.2016 .1193636$

Grynberg M. The challenge of fertility preservation in cancer patients: a special focus issue from Future Oncology. Future Oncol. 2016;12:1667-9. PMID: 27339296 DOI: $10.2217 /$ fon-2016-0250

Ferlay J, Soerjomataram I, Ervik M, Dikshit R, Eser S, Mathers C, Rebelo M, Parkin DM, Forman D, Bray F. GLOBOCAN 2012 cancer incidence and mortality worldwide: IARC cancerbase No. 11. Lyon: International Agency for Research on Cancer; 2013.

Kim SY, Kim SK, Lee JR, Woodruff TK. Toward precision medicine for preserving fertility in cancer patients: existing and emerging fertility preservation options for women. J Gynecol Oncol. 2016;27:e22. PMID: 26768785 DOI: $10.3802 /$ jgo.2016.27.e22

Lambertini M, Del Mastro L, Pescio MC, Andersen $C Y$, Azim HA Jr, Peccatori FA, Costa M, Revelli A, Salvagno F, Gennari A, Ubaldi FM1, La Sala GB, De Stefano C, Wallace $W H$, Partridge $A H$, Anserini P. Cancer and fertility preservation: international recommendations from an expert meeting. BMC Med. 2016;14:1. PMID: 26728489 DOI: $10.1186 / \mathrm{s} 12916-015-0545-7$

Loren AW, Mangu PB, Beck LN, Brennan L, Magdalinski AJ, Partridge $A H$, Quinn $G$, Wallace $W H$, Oktay K; American Society of Clinical Oncology. Fertility preservation for patients with cancer: American Society of Clinical Oncology clinical practice guideline update. J Clin Oncol. 2013;31:2500-10. PMID: 23715580 DOI: 10.1200/JCO.2013.49.2678

Niemasik EE, Letourneau J, Dohan D, Katz A, Melisko M, Rugo $H$, Rosen $M$. Patient perceptions of reproductive health counseling at the time of cancer diagnosis: a qualitative study of female California cancer survivors. J Cancer Surviv. 2012;6:324-32. PMID: 22752834 DOI: $10.1007 / \mathrm{s} 11764-012-0227-9$

Peccatori FA, Azim HA Jr, Orecchia R, Hoekstra HJ, Pavlidis N, Kesic V, Pentheroudakis G; ESMO Guidelines Working Group. Cancer, pregnancy and fertility: ESMO Clinical Practice Guidelines for diagnosis, treatment and followup. Ann Oncol. 2013;24:vi160-70. PMID: 23813932 DOI: 10.1093/annonc/mdt199

Peretti-Watel P. VICAN 2: La vie deux ans après un diagnostic de cancer. Paris: Institut National du Cancer; 2014.

Preaubert L, Pibarot M, Courbiere B. Can we improve referrals for fertility preservation? Evolution of practices after the creation of a fertility network. Future Oncol. 2016;12:21757. PMID: 27513104 DOI: $10.2217 /$ fon-2016-0240 
Rodriguez-Wallberg KA, Oktay K. Fertility preservation medicine: options for young adults and children with cancer. J Pediatr Hematol Oncol. 2010;32:390-6. PMID: 20502358 DOI: 10.1097/MPH.0b013e3181dce339

Rojas K, Stuckey A. Breast Cancer Epidemiology and Risk Factors. Clin Obstet Gynecol. 2016;59:651-72. PMID: 27681694 DOI: $10.1097 / G R F .0000000000000239$

Siegel R, Naishadham D, Jemal A. Cancer statistics, 2012. CA Cancer J Clin. 2012;62:10-29. PMID: 22237781 DOI: 10.3322/caac. 20138

Tschudin S, Bitzer J. Psychological aspects of fertility preservation in men and women affected by cancer and other life-threatening diseases. Hum Reprod Update. 2009;15:587-97. PMID: 19433413 DOI: $10.1093 /$ humupd/dmp015

Warner E, Yee S, Kennedy E, Glass K, Foong S, Seminsky M, Quan ML. Oncofertility Knowledge, Attitudes, and Practices of Canadian Breast Surgeons. Ann Surg Oncol. 2016;23:3850-9. PMID: 27431414 DOI: $10.1245 / \mathrm{s} 10434-016-5423-9$
Woodruff TK. The emergence of a new interdiscipline: oncofertility. Cancer Treat Res. 2007;138:3-11. PMID: 18080653

Woodruff TK. The Oncofertility Consortiumaddressing fertility in young people with cancer. Nat Rev Clin Oncol. 2010;7:466-75. PMID: 20498666 DOI: $10.1038 /$ nrclinonc. 2010.81

Woodruff TK. Oncofertility: a grand collaboration between reproductive medicine and oncology. Reproduction. 2015;150:S1-10. PMID: 26130814 DOI: $10.1530 / R E P-15-0163$

Yee S, Abrol K, McDonald M, Tonelli M, Liu KE. Addressing oncofertility needs: views of female cancer patients in fertility preservation. J Psychosoc Oncol. 2012;30:331-46. PMID: 22571247 DOI: 10.1080/07347332.2012.664257 